\title{
A Gesture-Based Educational System that Integrates Simulation and Molecular Visualization to Teach Chemistry
}

\author{
https://doi.org/10.3991/ijet.v17i04.26503 \\ Shaykhah S. Aldosari ${ }^{1,2(\bowtie)},{\text { Bogdan } \text { Ghita }^{2} \text {, Davide Marocco }}^{3}$ \\ ${ }^{1}$ Princess Nourah Bint Abdulrahman University, Riyadh, Saudi Arabia \\ ${ }^{2}$ Plymouth University, Plymouth, United Kingdom \\ ${ }^{3}$ University of Naples Federico II, Naples, Italy \\ ssaldossary@pnu.edu.sa
}

\begin{abstract}
Technology has proven effective in enhancing teaching methods. Gesture-based applications have a high potential for use in the development of teaching methods in schools. Simulation and 3D visualization, in particular, are some of the most important technologies that positively affected education. The implementation of these technologies in the education sector can determine students' potential and enhance their interest in learning in scientific fields. This study explored the use of a chemistry education system that integrates virtual simulation and molecular visualization and uses a Leap Motion controller to teach chemistry in secondary schools. The sample comprised 113 students enrolled in four different classes in a public secondary school in Saudi Arabia. The data were analyzed using an ANOVA test to compare the results. The results indicate that the students who used the proposed educational system achieved better learning results than the students who participated in theoretical classroom learning only. Moreover, students who used the proposed educational system learned microscopic-level concepts better than those who used a real chemistry laboratory. Finally, combining simulation and molecular visualization and using gesture-based technology has a significant and positive effect on the students' learning experience, as demonstrated by the results of this study which contributes to the development of education through the utilization of modern technology.
\end{abstract}

Keywords - chemistry, simulation, e-learning, gesture-based technology, virtual labs, 3D visualization

\section{Introduction}

Technology improves all aspects of daily life, bringing various benefits in different fields including education. Recently, a significant amount of research has been focusing on integrating the latest technological advances into the teaching and learning practices in order to improve the process. This scientific study aims to develop and implement visualization technologies in the education process to support and 
strengthen the curriculum delivery and solve discrepancies and limitations in existing methods. This leads to the advancement of leadership abilities that improve the learner's talents and expertise by using modern instructional methods that incorporate technology [1], [2], [3].

Teaching a subject is heavily dependent on the specifics of the area. While some subjects, such as mathematics or literature, may require very little hands-on, physical interaction, some others, such as physics, rely on experimentation and physical interaction to complete the understanding of a subject and some, such as chemistry, require a complex mix of theoretical, experimental, and physical observation of phenomena for a full learning experience. Moreover, chemistry is a complex subject to teach from both a teaching and a learning aspect. Students may struggle to grasp scientific and practical aspects, while instructors may find it difficult to clarify topics such as chemical reactions, bonding, chemical equilibrium, the orbital principle, and atomic structures [4], [5]. For several years, many studies have attempted to identify the origins and causes of difficulties in comprehending chemistry principles [6], [7]. It was concluded that the abstract essence of the material is the key factor in the complexity of studying chemistry [5]. Conventional teaching approaches in chemistry laboratories are inefficient in promoting students' comprehension of scientific principles without allowing for any interaction with real-world results [5]. Furthermore, it has many obstacles, such as a shortage of funding and supplies and safety concerns [8]. Accordingly, technologies play a significant role in chemistry education and in overcoming its difficulties. Chemistry concepts can be addressed using advanced chemistry education systems, such as virtual lab systems and molecular visualizations [9] - [12]. Virtual reality is a technology that simulates real-world environments and improves user interaction experience through different features and reactions. Virtual reality can be used in education and training to allow students to use the virtual laboratory without time and cost constraints, apply practical skills correctly, and provide many other advantages [13].

Over the years, the advancement of gesture-based technology has introduced major developments and innovations to education that have been adopted in courses and educational systems. This technology allows for the integration of actual concepts with theoretical concepts and increases student engagement [14], [15]. The use of gesture-based technology in education have shown exceptional results in learning in various fields [16] - [19]. One of the most notable gesture-based devices for humancomputer interaction (HCI) is the Leap Motion controller. This device has many features that allow it to recognize different hand gestures and enable interaction with high accuracy [20], [21]. The proposed chemistry education system uses the Leap Motion controller and integrates both the macroscopic and microscopic levels of chemistry.

This research aims to examine a virtual gesture-based educational system designed for secondary school students that combines chemistry simulations and molecular visualizations to enhance the teaching process and improve the students' learning achievements and understanding of chemistry concepts on different levels. It allows students to interact with virtual lab tools through hand gestures to increase student's engagement and interest in chemistry. In addition, it utilizes molecular visualization 
techniques in chemistry teaching to overcome difficulties in understanding and visualizing complex and abstract concepts. The effectiveness of the learning system in a real school setting is evaluated and compared with results obtained through traditional non-technology teaching methods. The results demonstrate the ability of the system to overcome difficulties faced by both students and teachers. The results also suggest that students' learning achievements can be significantly improved using the proposed educational system. The system provides an alternative teaching tool for teachers where students can conduct experiments anytime and anywhere, helping them comprehend chemistry concepts.

This paper is organized as follows. Section 2 introduces related work on the use of virtual chemistry labs and gesture-based interaction in education. Section 3 outlines the proposed educational system, then Section 4 presents the system testing results, including system usability testing and an interview study. The experimental methodology and procedures are presented in Section 5. In Section 6, the experimental results are discussed. Section 7 presents a conclusion and avenues for future work.

\section{Related work}

A virtual chemistry lab is a set of computer programs that allow students to experiment with chemistry protocols in a virtual environment. This set of computer programs usually includes online software or applications with predefined scenarios in which students perform experiments with their own computers [13], [22].

There are numerous benefits to using virtual chemistry labs. The most significant benefit is a safer environment for students to carry out chemistry experiments [23]. Other benefits include time flexibility and not requiring high budgets. Additional benefits in science subjects were discussed in [11], [24], [25].

Researchers have been keen to investigate students' perspectives and responses to the implementation of virtual reality-based labs and simulation in chemistry [25], [26]. For example, Pyatt and Sims [24] conducted research on the effectiveness of a simulated chemistry experiment in teaching chemistry. They found that the students showed positive attitudes toward virtual experiences and that the simulated experience provided more opportunities to manipulate and explore experimental variables than a physical experience.

Gesture-based interfaces are a natural and intuitive approach to HCI based on the recognition of hand gestures [27]. Many applications and devices are using gesturebased technology to replace traditional input devices, such as a keyboard and mouse, in various fields, such as entertainment, healthcare, training, and education [28] [32].

Many studies have investigated the impact of using gesture-based technology in education [17], [18], [19]. Sheu and Chen [33] reviewed the applications of gesturebased computing in the field of education. The authors claimed that the traditional model of education could be revolutionized with the implementation of gesture-based computing and simulation programs. In another study, Ferreira et al. [18] explored the use of a 3D printed hysteroscopy model and the Leap Motion controller to monitor 
hand movements during a simulated hysteroscopy. Talib et al. [34] examined how to teach an organic chemistry course using an educational application relying on molecule animation and electron-moving techniques. The students obtained a greater understanding of the structure of organic reactions by using the electron-moving methodology than by using the traditional teaching approach. J. Lee et al. [35] proposed a gesture-based method for immersive 3D material manipulation to explore and interpret DNA structures and protein molecules, which provided benefits to students and teachers. Various systems were developed to increase the efficiency of molecular visualization such as the PyMOL mControl visualization system [36] and Eukaryo [37].

\section{A Gesture-based educational system for teaching chemistry}

Scientists have examined various methods for presenting teaching materials that incorporate recent technological advances [3]. The aim of this study was to design and implement an educational system for chemistry experiments that simulated reallife experiments enhanced with molecular visualization. This work used the Leap Motion controller (Figure 1) in education and simulation fields to facilitate the learning process [21]. The Leap Motion controller is capable of recognizing hand gestures and has great potential, as it provides new intuitive methods of interaction that feel natural. The Leap Motion controller can identify and track the rotations and positions of both of the user's hands simultaneously, along with their fingers [20], [21]. The Leap Motion controller has applications in many diverse fields due to its high resolution and accuracy [38], [39], [40].

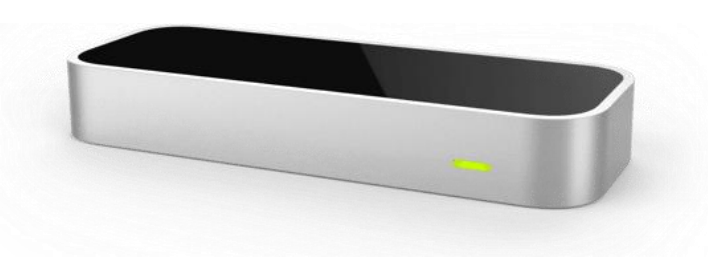

Fig. 1. The Leap Motion controller [21]

The system features a number of chemistry experiments from the secondary school chemistry curriculum in Saudi Arabia. These experiments allow students to experience a real chemistry lab by completing experimental steps in a virtual lab at the macroscopic level. The system simulates all the experimental procedures and results as in a real laboratory. Users can interact directly with glassware and chemical substances using physical movements at the macroscopic level. The experiment steps can be completed with either the Leap Motion controller or the mouse, as an alternative device. It features the microscopic view where students can view and interact with the molecules and chemical bonds. Users can move and rotate the atoms, molecules, and bonds using hand gestures and observe the chemical interactions between the molecules, how bonds break, and how new bonds are constructed. The proposed educa- 
tional system was developed using the Unity3D engine and C\# scripting language (see Figure 2) [41].

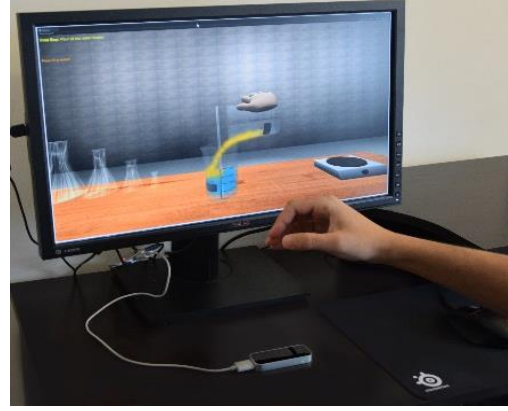

(a)

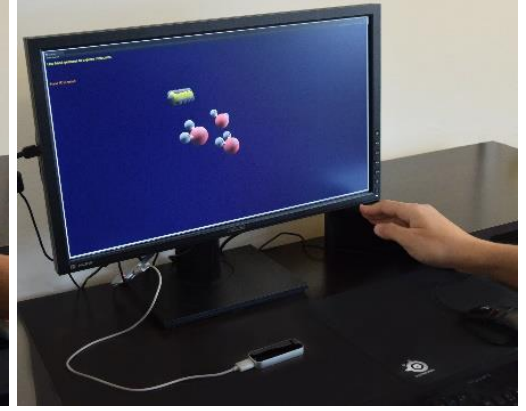

(b)

Fig. 2. A user uses the proposed system at (a) the macroscopic level, (b) the microscopic level

\section{Previous studies on the proposed system}

To test the proposed chemistry education system and examine its strengths and deficiencies before applying it in a school setting, two research methods were applied. First, five teachers who had experience teaching chemistry to secondary school students tested the proposed system. They were then interviewed to verify the effectiveness of the proposed system. Second, usability testing was conducted to evaluate the proposed system's usability and design. The interview study and system usability testing procedures and results were published in [42]. This section summarizes the findings of the interview study and the usability testing study.

\subsection{System usability testing}

The objective of a usability test is to evaluate the usability of the design, the interface, and the learning effectiveness of a system. Usability testing of the proposed system was organized at the College of Computer and Information Sciences at Princess Nourah bint Abdulrahman University (PNU) in Riyadh, Saudi Arabia. Forty-five participants were selected to assure reliable results. Participants were asked to complete a short background questionnaire that was used to evaluate the system. Then, they completed a survey on their opinions about the system after using it with the Leap Motion controller. Participants gave their responses on 13 subjective measures using a 5-point Likert scale.

The results showed that most users could use the Leap Motion controller regardless of whether they have used it before. It increases user engagement and students better comprehend the experiments. These results indicate the potential of the proposed chemistry education system to provide more comprehensible information and increase student engagement through a realistic simulation. 


\subsection{Interview study}

In-depth impressions about the proposed system were gathered by interviewing five chemistry teachers. A qualitative content analysis method was chosen to analyze and evaluate the participants' responses in the interviews. Details about the interview results can be found in [42].

In summary, the interviewees gave positive feedback regarding the integration of gesture-based devices with the macroscopic and microscopic levels of experiments. All participants found the system simple and easy to use and concluded that tasks could be completed easily without additional help. The interview findings show that several related issues might be significantly reduced through the use of the proposed system; these issues included shortage of materials, a high number of students per class, re-creation of experiments, and the formulation of exams.

\section{$5 \quad$ Designing the experiment}

This section describes the experiment, which was performed in a real school setting to assess the effectiveness of the proposed system in chemistry learning. The proposed educational system was used to teach chemistry in a secondary school, and students' performance on chemistry knowledge was examined. The results are also investigated to understand the specific characteristics of the system from a learning perspective. We hypothesized that using simulation and molecular visualization with gesture-based technology in chemistry education would improve the acquisition of chemistry knowledge and teaching methods.

\subsection{Experiment methodology}

The study used a pre-test and post-test design methodology in which three classes were administered pre-tests. After, students attended two lessons and two chemistry experiments. Finally, post-tests were administered. The tests were developed to measure chemistry knowledge and understanding of chemical processes. Experimental conditions changed for the three classes between the first and second lessons and experiments. We refer to these conditions as Lesson_l and Lesson_2 in the following.

In Lesson_l, after the administration of the same multiple-choice test top all three classes, all students attended a theoretical lesson about why oil and water do not mix, taught by the usual chemistry teachers (different for each class). After the lesson, some students applied their knowledge in a real chemistry lab, while others used the educational system proposed in this study. Some students received only the theoretical lesson and did not participate in the lab or virtual work.

In Lesson_2, the three classes repeated the procedures on a different subject, namely salt hydrolysis, to study the change of three different types of salts when added to water, as each produces a different reaction. This time, the classes were arranged differently to cross-check the effects of different methods on the same subjects and to avoid situations in which students could attend the same experimental condition twice. 
The two multiple-choice tests used as pre- and post-tests in the two experimental conditions were paper-based exams prepared by a secondary school chemistry teacher, which reflected the usual method used to evaluate students' learning in schools. The pre-tests were used to assess prior student knowledge about the lesson subject, while the post-tests investigated student acquisition of conceptual knowledge and experimental skills after the chemistry lessons.

In Lesson_1, the test consisted of five multiple-choice questions designed to determine students' understanding of both the macroscopic and microscopic levels of the first chemistry experiment (mixing oil and water). Three questions concerned experimental procedures at the macroscopic level. Two questions were used to assess the students' understanding of the chemistry concepts at the microscopic level of the experiment.

Similarly, in Lesson_2, the test consisted of 14 multiple-choice questions designed to determine students' understanding of both the macroscopic and microscopic levels of the second chemistry experiment (salt hydrolysis). The first four questions were designed to assess the students' understanding of the experimental procedures at the macroscopic level of the experiment. The remaining questions were used to assess the participants' understanding of the chemistry concepts at the microscopic level of the experiment.

\subsection{Participants}

A total of 113 secondary school students participated in this study. Of these, 83 students participated in Lesson_1, and 85 students participated in Lesson_2. All participants were female, and their average age was 17. All participants were in secondary school in Saudi Arabia and had a basic knowledge of chemistry.

\subsection{Experiment procedure}

The entire experiment lasted two weeks. The experiment used four classes and alternated between classes in each case to guarantee that no students used the same system twice.

Lesson_l was conducted in week 1. The participants were divided into three groups based on their classes: Class1 $(n=26)$, Class2 $(n=28)$, and Class3 $(n=29)$. In the first stage, the students took the pre-test to assess their prior knowledge about the Lesson_l subject before the lesson. In the second stage, after the theoretical lesson, the three classes were assigned three different experimental conditions: Class 1 underwent the theoretical lesson only without applying the theoretical concepts. Class 2 applied the theory in a chemistry experiment conducted in a real lab. Class 3 applied the theory using the proposed educational simulation system and interacted with the system using the Leap Motion controller. In the third stage, all three classes took the post-test to evaluate what they had learned.

Lesson_2 was conducted in week 2. The participants were grouped as follows: Class1 $(n=26)$ and Class3 $(n=29)$, the same as above, and Class4 $(n=30)$. In the first stage, the students took the pre-test to assess their prior knowledge about the 
Lesson_2 subject before the lesson. In the second stage, after the theoretical lesson, the students in Classl used the proposed educational system to explore the learned theory, interacting with the system using the Leap Motion controller. The students in Class 3 applied the learned theory in the real chemistry lab. The students in Class 4 only underwent the theoretical lesson without practical experience. In the third stage, all three classes completed the post-test to measure their retention. The procedures for each case in this experiment, the three stages of each case, and the class arrangements are shown in Figure 3.

Lesson_1

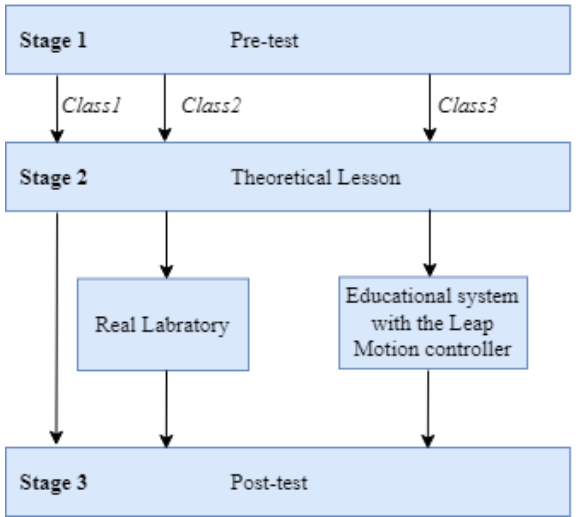

Lesson_2

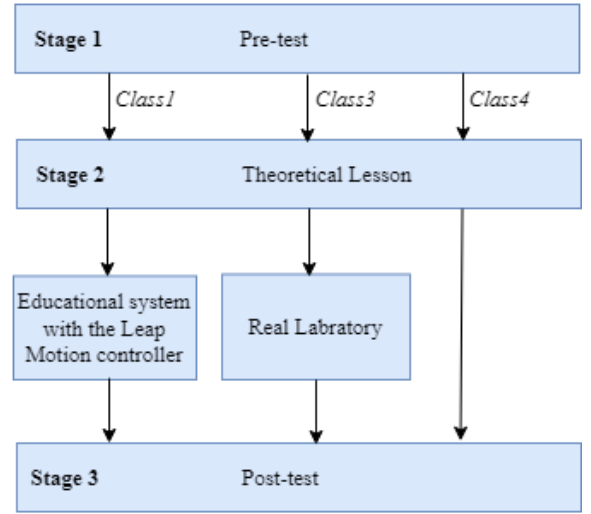

Fig. 3. Experimental procedure

\subsection{Experimental analyses}

The data analysis was conducted in two sections for each lesson to test two specific hypotheses using a one-way ANOVA test. In the first experimental analysis, the teaching method was the independent variable. This was either a) use of the proposed educational system with the theoretical lesson, b) use of the real lab with the theoretical lesson, or c) use of the theoretical lesson only (the control group). Learning achievement was the dependent variable. Our first hypothesis was that experiential learning would produce better test scores with respect to the control group, thus demonstrating that the proposed system and the real lab are comparable from a learning achievement point of view.

A second analysis compared the change in learning achievement among specific questions on the tests: those related to knowledge of the macroscopic level of the chemistry lessons and those related to knowledge of the microscopic level of the chemistry lessons. The second hypothesis was that students who used the proposed system would understand the microscopic-level concepts better than the control group or the students who used the real lab because the proposed system would allow students to visualize the molecular processes involved in the chemical reactions at hand. Post-hoc comparisons with the Bonferroni correction were used to test the statistical 
hypothesis and identify the significant differences between the classes. The significance level was set at $(p<.05)$.

\section{$6 \quad$ Results and discussion}

In this section, the results for each lesson are reported, and pedagogical indications are derived. The score for each student was the sum of the answers to the multiplechoice questions on the exam tests. Correct answers were counted as one, and wrong answers were counted as zero. No penalty was given for wrong answers. "I don't know" answers were counted as wrong answers.

\subsection{Lesson_1 results}

The mean scores for the pre-test out of 5 were $0.58,0.43$, and 0.79 for Class 1 , Class2, and Class3, respectively. The standard deviations (SDs) were 0.703, 0.79, and 0.907 for Class1, Class2, and Class3, respectively. Table 1 illustrates the results of the three conditions. There were no significant differences between the three classes in the pre-test $(p=.717$ ) according to the independent ANOVA test results (see Table 2 ). Therefore, the prior knowledge of students in all three classes before the start of the first case study was similar.

While the pre-test results confirmed that there were no prior knowledge differences among the three classes, the post-test learning achievements of the classes were studied to identify the effects of the proposed educational system. The mean scores for the post-test out of 5 were 3.31, 3.71, and 4.10 for Class 1, Class2, and Class3, respectively. The SDs were 1.12, 1.084, and 0.817 for Class1, Class2, and Class3, respectively (see Table 1). The one-way ANOVA identified significant differences among the three conditions in the post-test $[F(2,80)=4.239, p=.018]$.

Table 2 shows the effects and multiple comparisons of the three static conditions. Post-hoc comparisons using the Bonferroni correction indicated significant differences between the learning achievements of Class1 and Class3 $(p=.014)$; however, there were no significant differences between the conditions of Class1 and Class2 ( $p$ $=.432)$ or Class 2 and Class3 $(p=.452)$.

Learning Achievement at the Macroscopic Level. In the first lesson test, three questions targeted the participants' understanding of the experimental concepts and information about the macroscopic level of the lesson, as established by the chemistry teachers. The post-test answers to these questions were examined to analyze the students' learning achievements in terms of their knowledge of the macroscopic level of the chemistry lesson. The mean scores for the macroscopic level of the post-test out of 3 were 2.42, 2.54, and 2.38 for Class1, Class2, and Class3, respectively. The SDs were 0.703, 0.576, and 0.622 for Class1, Class2, and Class3, respectively (see Table $1)$. Results indicated no significant differences between the classes $[F(2,80)=0.458$, $p=.634]$. 
Table 1. Learning achievements of all three classes after the first lesson and chemistry experiment

\begin{tabular}{|l|c|c|c|c|c|}
\hline \multirow{4}{*}{ Study Case } & Static Condition & N & Mean & Std. Deviation & Std. Error \\
\hline \multirow{3}{*}{ Pre-test } & Class1 & 26 & 0.580 & 0.703 & 0.138 \\
\cline { 2 - 6 } & Class2 & 28 & 0.430 & 0.790 & 0.149 \\
\cline { 2 - 6 } & Class3 & 29 & 0.590 & 0.907 & 0.168 \\
\hline \multirow{3}{*}{ Post-test } & Class1 & 26 & 3.310 & 1.123 & 0.220 \\
\cline { 2 - 6 } & Class2 & 28 & 3.710 & 1.084 & 0.205 \\
\cline { 2 - 6 } & Class3 & 29 & 4.100 & 0.817 & 0.152 \\
\hline \multirow{3}{*}{ Macroscopic view of the post-test } & Class1 & 26 & 2.420 & 0.703 & 0.138 \\
\cline { 2 - 6 } & Class2 & 28 & 2.540 & 0.576 & 0.109 \\
\cline { 2 - 6 } & Class3 & 29 & 2.380 & 0.622 & 0.115 \\
\hline \multirow{3}{*}{ Microscopic view of the post-test } & Class1 & 26 & 0.880 & 0.766 & 0.150 \\
\cline { 2 - 6 } & Class2 & 28 & 1.180 & 0.772 & 0.146 \\
\cline { 2 - 6 } & Class3 & 29 & 1.720 & 0.528 & 0.098 \\
\hline
\end{tabular}

Table 2. ANOVA and post-hoc results of the learning achievements of all three classes after the first lesson and chemistry experiment

\begin{tabular}{|c|c|c|c|c|}
\hline Study case & Effects & Df & $\mathbf{F}$ & Sig. \\
\hline \multirow{4}{*}{ Pre-test } & Condition & 2,80 & 0.335 & 0.717 \\
\hline & Class 1 v Class 2 & & & \\
\hline & Class1 v Class3 & & & \\
\hline & Class 2 v Class 3 & & & \\
\hline \multirow{4}{*}{ Post-test } & Condition & 2,80 & 4.239 & $0.018^{*}$ \\
\hline & Class1 v Class2 & & & 0.432 \\
\hline & Class1 v Class3 & & & $0.014^{*}$ \\
\hline & Class 2 v Class 3 & & & 0.452 \\
\hline \multirow{4}{*}{ Macroscopic view of the post-test } & Condition & 2,80 & 0.458 & 0.634 \\
\hline & Class1 v Class 2 & & & \\
\hline & Class1 v Class 3 & & & \\
\hline & Class 2 v Class 3 & & & \\
\hline \multirow{4}{*}{ Microscopic view of the post-test } & Condition & 2,80 & 10.450 & $0.000^{*}$ \\
\hline & Class1 v Class2 & & & 0.372 \\
\hline & Class1 v Class 3 & & & $.000^{*}$ \\
\hline & Class 2 v Class 3 & & & $0.012^{*}$ \\
\hline
\end{tabular}

Learning Achievement at the Microscopic Level. The learning achievements among participants regarding their knowledge of the microscopic level of the chemistry lesson were examined by analyzing their answers to the two related questions in the post-test. According to the chemistry teachers of the classes, these questions targeted students' understanding of the experimental concepts and information about the microscopic level of the lesson. The means and SDs for each class's learning achievement regarding the microscopic level of the post-test with maximum scores of 
2 are shown in Table 1. The one-way ANOVA identified significant differences $[F(2$, $80)=10.45, p=.000]$. Post-hoc comparisons using the Bonferroni correction indicated significant differences in the exam scores between Class1 and Class3 $(p=.000)$ and between Class 2 and Class $3(p=.012)$. There were no significant differences between Class1 and Class2 $(p=.372)$.

\subsection{Lesson 2 results}

Table 3 illustrates the results of the three conditions in the pre-test of the second lesson. The mean scores for the pre-test out of 14 were 1.46, 1.24, and 1.73 for Class1, Class3, and Class4, respectively. The SDs were 1.272, 1.154, and 1.311 for Class1, Class3, and Class4, respectively. According to the independent ANOVA test results, there were no significant differences between these three classes on the pretest $(p=.321$; see Table 4$)$. The pre-test results also confirmed that there were no prior knowledge differences between the three classes. Therefore, the prior knowledge of the students in these three classes before the start of the first case of the study was similar. Learning achievement was studied in the post-test stage to identify the effect of the proposed educational system and the lab as learning tools.

Table 3 displays the post-test results with maximum scores of 14 of the three conditions after the second lesson. The one-way ANOVA identified significant differences between the three conditions in the post-test $[F(2,82)=11.723, p=.000]$. Table 4 shows the effects and multiple comparisons of the three static conditions. Post-hoc comparisons using the Bonferroni correction indicated that there were significant differences in learning achievements between Class1 and Class4 $(p=.000)$ and between Class 3 and Class $4(p=.013)$. In contrast, there were no significant differences between Class 1 and Class3 $(p=.171)$.

Learning Achievement at the Macroscopic Level. Responses to the four posttest questions related to knowledge of the macroscopic level of the chemistry lesson were examined to determine learning achievement. The chemistry teachers stated that these questions targeted students' understanding of the experimental concepts and information about the macroscopic level of the lesson. The means and SDs for the learning achievement at the macroscopic level of the post-test with maximum scores of 4 are displayed in Table 3. Results indicated no significant differences between conditions $[F(2,82)=2.407, p=.096]$.

Learning Achievement at the Microscopic Level. Responses to the 10 post-test questions related to students' understanding of the macroscopic concepts and models of the chemistry lesson, according to the chemistry teachers, were also studied to determine learning achievement. The means and SDs for the learning achievement at the microscopic level of the lesson out of 10 are displayed in Table 3 . The one-way ANOVA identified significant differences $[F(2,82)=13.723, p=.000]$. Post-hoc comparisons using the Bonferroni correction indicated significant differences in exam scores between Class1 and Class3 $(p=.010)$ and between Class1 and Class4 ( $p=$ $.000)$. There were no significant differences between Class 3 and Class 4 ( $p=.081$; see Table 4). 
Paper-A Gesture-Based Educational System that Integrates Simulation and Molecular Visualization to...

Table 3. Learning achievements of all three classes after the second lesson and chemistry experiment

\begin{tabular}{|l|c|c|c|c|c|}
\hline \multirow{4}{*}{ Study Case } & Static Condition & $\mathbf{N}$ & Mean & Std. Deviation & Std. Error \\
\hline \multirow{4}{*}{ Pre-test } & Class1 & 26 & 1.46 & 1.272 & 0.249 \\
\cline { 2 - 6 } & Class3 & 29 & 1.24 & 1.154 & 0.214 \\
\cline { 2 - 6 } & Class4 & 30 & 1.73 & 1.311 & 0.239 \\
\hline \multirow{4}{*}{ Post-test } & Class1 & 26 & 11.23 & 2.103 & 0.413 \\
\cline { 2 - 6 } & Class3 & 29 & 9.93 & 2.534 & 0.471 \\
\cline { 2 - 6 } The macroscopic view of the post-test & Class4 & 30 & 8.03 & 2.748 & 0.502 \\
\cline { 2 - 6 } & Class1 & 26 & 2.96 & 1.216 & 0.238 \\
\cline { 2 - 6 } & Class3 & 29 & 3.45 & .827 & 0.154 \\
\hline \multirow{3}{*}{ The microscopic view of the post-test } & Class4 & 30 & 2.83 & 1.289 & 0.235 \\
\cline { 2 - 6 } & Class1 & 26 & 8.27 & 1.458 & 0.286 \\
\cline { 2 - 6 } & Class3 & 29 & 6.48 & 2.370 & 0.440 \\
\cline { 2 - 6 } & Class4 & 30 & 5.20 & 2.511 & 0.458 \\
\hline
\end{tabular}

Table 4. ANOVA and post-hoc results of the learning achievements of all three classes after the second lesson and chemistry experiment

\begin{tabular}{|c|c|c|c|c|}
\hline Study case & Effects & Df & $\mathbf{F}$ & Sig. \\
\hline \multirow{4}{*}{ Pre-test } & Condition & 2,82 & 1.152 & 0.321 \\
\hline & Class 1 v Class 3 & & & \\
\hline & Class1 v Class 4 & & & \\
\hline & Class 3 v Class 4 & & & \\
\hline \multirow{4}{*}{ Post-test } & Condition & 2,82 & 11.723 & $0.000^{*}$ \\
\hline & Class 1 v Class 3 & & & 0.171 \\
\hline & Class 1 v Class 4 & & & $0.000^{*}$ \\
\hline & Class 3 v Class 4 & & & $0.013^{*}$ \\
\hline \multirow{4}{*}{ Macroscopic view of the post-test } & Condition & 2,82 & 2.407 & 0.096 \\
\hline & Class1 v Class 3 & & & \\
\hline & Class1 v Class4 & & & \\
\hline & Class 3 v Class 4 & & & \\
\hline \multirow{4}{*}{ Microscopic view of the post-test } & Condition & 2,82 & 13.723 & $0.000^{*}$ \\
\hline & Class1 v Class3 & & & $0.010^{*}$ \\
\hline & Class 1 v Class 4 & & & $0.000^{*}$ \\
\hline & Class 3 v Class 4 & & & 0.081 \\
\hline
\end{tabular}

${ }^{*}$ Denotes statistical significance.

\subsection{Discussion}

The results support the first hypothesis and indicate that students would better understand a chemistry lesson using the proposed system than students who were just given the theoretical lesson without physically performing the experiment. In addition, the students who applied the lesson using the proposed system would have the 
same learning achievements as the students who applied the lesson in a real lab. Therefore, we conclude that the proposed system can be a valid alternative replacement for real-world experiments in chemistry labs.

We are aware of a number of limitations of the presented study that might affect this result, which are as follows:

- It was observed that each class had a different teacher. Therefore, the theoretical lessons were given by different teachers in each class, which could have influenced the learning achievement.

- To assess learning achievement, this study used an exam prepared by a chemistry teacher, which could be inappropriate. It was observed by the researcher that the exam was slightly unbalanced in covering macroscopic- and microscopic-level information. Particularly, most of the questions covered the microscopic level of the lessons, while few covered the macroscopic level, especially in the second lesson. In addition, a number of questions focused on similar concepts, while others were neglected. Thus, the current results might change if researchers prepare the evaluation exam differently.

- The students were familiar with the real lab and had used it many times before for different lessons during their school lives. In contrast, the students were using the proposed educational system and the Leap Motion controller for the first time. This could distract students' attention and reduce focus on the lesson, and thus would certainly affect the achievement of the study. This is important to the present study in that several researchers have noted that the use of digital devices in class can distract students during lectures [43]. In addition, some researchers have found that students do not always believe that virtual labs are realistic, which could have an effect on the results [44].

The results also support the second hypothesis and show that the students who used the proposed system with the Leap Motion controller had better learning achievement related to their understanding of the microscopic level of the lesson than the students who used the real lab or had the theoretical lesson only. These results support the main purpose of the proposed educational system, which is to combine practical knowledge with molecular representation to understand chemistry theories and models and to assist users in understanding molecular structures and chemical bonds.

Overall, these results support the main research hypothesis that using simulation and molecular visualization with gesture-based technology in chemistry education favors the acquisition of chemistry knowledge and enhances the teaching method. The main finding of this study is that the proposed system's integration of gesture-based technology and molecular visualization allows students to interact with and visualize abstract chemistry concepts. Accordingly, this system enhances the understanding of complex and abstract concepts and helps in overcoming chemistry learning difficulties. It increases students' interactions and provides a more realistic simulation by integrating gesture-based technology and simulation.

Also, this study further confirms that active learning in many forms has a clear advantage over passive learning procedures. Moreover, with respect to the peculiarity of the proposed system, the interchangeability between a real and virtual lab has clear 
advantages in terms of fruition. For example, students can complete the experiments at any time, any place. This would solve the problem of how to have students complete experiments when they miss class or the problem of increasing class sizes, according to the interviewed teachers. The proposed system can also be used to help students prepare for exams by reviewing their information and identifying their weaknesses. Furthermore, the proposed system avoids issues of lab availability, missing necessary materials, and hazardous materials. Finally, the system can help in distance learning delivery in e-learning courses or massive open online courses.

In general, the results of this study show that by combining chemistry simulation with molecular visualization concepts, students can understand the objective of the chemistry experiments just as well when using the proposed system as in the real lab. The findings show that the system can help students develop a better understanding of the microscopic explanations and concepts of chemistry experiments than in the real lab. Thus, we conclude that the proposed educational system increases the opportunity for students to apply and understand experimental concepts and solves many issues faced by teachers in teaching chemistry.

\section{Conclusion}

This work presented a 3D chemistry education system based on gesture-based technology using the Leap Motion controller that can be used to augment the learning process for secondary school and undergraduate students. It allows students to display and interact with macroscopic and microscopic levels through simulated learning and molecular modeling learning approaches using the same system. We believe that this system has an advantage over available systems in chemistry that do not combine these different levels.

Based on the findings, we recommend the combined use of the proposed system and real-life laboratories whenever possible, as the real lab favors the acquisition of practical skills. Nevertheless, this study also proves that it is sufficient to use the proposed educational system to improve chemistry learning when a real lab is not available, such as in the case of distance learning during the COVID-19 pandemic, absence from class, and the unavailability or risk of chemicals. The practical implementation of such a technology can also enable teachers to visualize concepts in chemistry that were previously unexplainable in traditional educational systems.

In conclusion, integrating gesture-based technology with simulation and molecular visualization improves students' acquisition of knowledge and enhances teaching methods. Gesture-based technologies can further improve the learning experience of students and can be used by any user with sufficient knowledge of handling such tools. It enables students to actively learn with increased interest. In future work, the proposed concept should be examined with different school subjects. In addition, more work is required to improve the developed system using a virtual reality headset and to evaluate the system in schools. 


\section{References}

[1] C. Buabeng-Andoh, "Factors influencing teachers' adoption and integration of information and communication technology into teaching: A review of the literature," Int. J. Educ. Dev. Using Inf. Commun. Technol., vol. 8, pp. 136-155, Jan. 2012.

[2] S. Ghavifekr and W. A. W. Rosdy, "Teaching and Learning with Technology: Effectiveness of ICT Integration in Schools," Int. J. Res. Educ. Sci., vol. 1, no. 2, pp. 175-191, Mar. 2015. https://doi.org/10.21890/ijres.23596

[3] R. Raja and P. C. Nagasubramani, "Impact of modern technology in education," J. Appl. Adv. Res., vol. 3, no. 1, p. 33, May 2018. https://doi.org/10.21839/jaar.2018.v3iS1.165

[4] B. Acar and L. Tarhan, "Effects of Cooperative Learning on Students' Understanding of Metallic Bonding," Res. Sci. Educ., vol. 38, no. 4, pp. 401-420, 2008. https://doi.org/10.10 07/s11165-007-9054-9

[5] A. T. Eticha and C. E. Ochonogor, "Assessment of Undergraduate Chemistry Students' Difficulties in Organic Chemistry," in 2015 ISTE International Conference on Mathematics, Science and Technology Education, 2015, pp. 285-296.

[6] A. L. de Quadros et al., "The knowledge of chemistry in secondary education: difficulties from the teachers' viewpoint," Educ. química, vol. 22, no. 3, pp. 232-239, 2011. https://do i.org/10.1016/S0187-893X(18)30139-3

[7] K. Osman and N. S. Sukor, "Conceptual Understanding in Secondary School Chemistry: A Discussion of the Difficulties Experienced by Students," Am. J. Appl. Sci., vol. 10, no. 5, pp. 433-441, May 2013. https://doi.org/10.3844/ajassp.2013.433.441

[8] Z. Tatli and A. Ayas, "Effect of a Virtual Chemistry Laboratory on Students' Achievement," Educ. Technol. Soc., vol. 16, no. 1, pp. 159-170, 2013.

[9] L. S. Nadelson, J. Scaggs, C. Sheffield, and O. M. McDougal, "Integration of Video-Based Demonstrations to Prepare Students for the Organic Chemistry Laboratory," J. Sci. Educ. Technol., vol. 24, no. 4, pp. 476-483, 2015. https://doi.org/10.1007/s10956-014-9535-3

[10] B. Rayan and A. Rayan, "Avogadro Program for Chemistry Education: To What Extent can Molecular Visualization and Three-dimensional Simulations Enhance Meaningful Chemistry Learning?," World J. Chem. Educ., vol. 5, no. 4, pp. 136-141, Jul. 2017. https:// doi.org/10.12691/wjce-5-4-4

[11] V. Potkonjak et al., "Virtual laboratories for education in science, technology, and engineering: A review," Comput. Educ., vol. 95, pp. 309-327, 2016. https://doi.org/10.1016/j.c ompedu.2016.02.002

[12] P. Hermosilla, P. Vázquez, A. Vinacua, and T. Ropinski, “A General Illumination Model for Molecular Visualization," Comput. Graph. Forum, vol. 37, no. 3, pp. 367-378, Jun. 2018. https://doi.org/10.1111/cgf.13426

[13] M. O. Onyesolu, "Virtual Reality Laboratories: An Ideal Solution to the Problems Facing Laboratory Setup and Management," in the World Congress on Engineering and Computer Science-WCECS 2009, 2009.

[14] K. Vermun, M. Senapaty, A. Sankhla, P. Patnaik, and A. Routray, "Gesture-Based Affective and Cognitive States Recognition Using Kinect for Effective Feedback during eLearning," in 2013 IEEE Fifth International Conference on Technology for Education (t4e 2013), 2013, pp. 107-110. https://doi.org/10.1109/T4E.2013.34

[15] B. Vogel, O. Pettersson, A. Kurti, and A. S. Huck, "Utilizing Gesture Based Interaction for Supporting Collaborative Explorations of Visualizations in TEL," in 2012 IEEE Seventh International Conference on Wireless, Mobile and Ubiquitous Technology in Education, 2012, pp. 177-181. https://doi.org/10.1109/WMUTE.2012.40 
[16] A. Baratè, L. A. Ludovico, and E. Oriolo, "Investigating Embodied Music Expression Through the Leap Motion: Experimentations in Educational and Clinical Contexts," in Computer Supported Education, 2019, pp. 532-548. https://doi.org/10.1007/978-3-030-21 $\underline{151-6 \_25}$

[17] P. Caligiana, A. Liverani, A. Ceruti, G. M. Santi, G. Donnici, and F. Osti, "An Interactive Real-Time Cutting Technique for 3D Models in Mixed Reality," Technologies, vol. 8, no. 2. 2020. https://doi.org/10.3390/technologies8020023

[18] S. C. Ferreira et al., "Empirical Evaluation of a 3D Virtual Simulator of Hysteroscopy Using Leap Motion for Gestural Interfacing," J. Med. Syst., vol. 44, no. 11, p. 198, 2020. https://doi.org/10.1007/s10916-020-01662-y

[19] X. Hu and Z. R. Han, "Effects of gesture-based match-to-sample instruction via virtual reality technology for Chinese students with autism spectrum disorders," Int. J. Dev. Disabil., vol. 65, no. 5, pp. 327-336, Oct. 2019. https://doi.org/10.1080/20473869.2019.160235 $\underline{0}$

[20] D. Bachmann, F. Weichert, and G. Rinkenauer, "Evaluation of the Leap Motion Controller as a New Contact-Free Pointing Device," Sensors, vol. 15, no. 1, pp. 214-233, Dec. 2014. https://doi.org/10.3390/s150100214

[21] Ultraleap, "Leap Motion Controller," 2020. [Online]. Available: https://www.ultraleap. com/product/leap-motion-controller/

[22] D. Vlachopoulos and A. Makri, "The effect of games and simulations on higher education: a systematic literature review," Int. J. Educ. Technol. High. Educ., vol. 14, no. 1, p. 22, Dec. 2017. https://doi.org/10.1186/s41239-017-0062-1

[23] C. Tuysuz, "The Effect of the Virtual Laboratory on Students' Achievement and Attitude in Chemistry," Int. Online J. Educ. Sci., vol. 2, pp. 37-53, Jan. 2010.

[24] K. Pyatt and R. Sims, "Virtual and Physical Experimentation in Inquiry-Based Science Labs: Attitudes, Performance and Access," J. Sci. Educ. Technol., vol. 21, no. 1, pp. 133147, 2012. https://doi.org/10.1007/s10956-011-9291-6

[25] J. Sentongo, R. Kyakulaga, and I. Kibirige, "The Effect of Using Computer Simulations in Teaching Chemical Bonding: Experiences with Ugandan Learners," Int. J. Educ. Sci., vol. 5, no. 4, pp. 433-441, Oct. 2013. https://doi.org/10.1080/09751122.2013.11890105

[26] M. M. L. Guerrero, "Using computer animation simulation in chemistry in order to solve students' misinterpretations and misconceptions about oxidation-reduction reactions," Int. J. Innov. Technol. Adapt. Manag., vol. 1, no. 10, 2014.

[27] V. A. Shanthakumar, C. Peng, J. Hansberger, L. Cao, S. Meacham, and V. Blakely, "Design and evaluation of a hand gesture recognition approach for real-time interactions," Multimed. Tools Appl., vol. 79, no. 25, pp. 17707-17730, 2020. https://doi.org/10.1007/s1 1042-019-08520-1

[28] V. Lahanas, C. Loukas, K. Georgiou, H. Lababidi, and D. Al-Jaroudi, "Virtual realitybased assessment of basic laparoscopic skills using the Leap Motion controller," Surg. Endosc., vol. 31, no. 12, pp. 5012-5023, 2017. https://doi.org/10.1007/s00464-017-5503-3

[29] É. Léger, J. Reyes, S. Drouin, D. L. Collins, T. Popa, and M. Kersten-Oertel, "Gesturebased registration correction using a mobile augmented reality image-guided neurosurgery system," Healthc. Technol. Lett., vol. 5, no. 5, pp. 137-142, 2018. https://doi.org/10.1049/ htl.2018.5063

[30] H. Qu, "Application of Kinect Technology in Blind Aerobics Learning," Int. J. Emerg. Technol. Learn. (iJET); vol 12, no. 12, Dec. 2017. https://doi.org/10.3991/ijet.v12i12.7960

[31] M. Zhang, Z. Zhang, Y. Chang, E.-S. Aziz, S. Esche, and C. Chassapis, "Recent Developments in Game-Based Virtual Reality Educational Laboratories Using the Microsoft Ki- 
nect," Int. J. Emerg. Technol. Learn. (iJET); vol. 13, no. 01, Jan. 2018. https://doi.org/10.3 991/ijet.v13i01.7773

[32] M. Sun, X. Wu, Z. Fan, and L. Dong, "Augmented Reality Based Educational Design for Children,” Int. J. Emerg. Technol. Learn. (iJET); vol. 14, no. 03, Feb. 2019. https://doi.org /10.3991/ijet.v14i03.9757

[33] F.-R. Sheu and N.-S. Chen, "Taking a signal: A review of gesture-based computing research in education," Comput. Educ., vol. 78, pp. 268-277, Sep. 2014. https://doi.org/10.1 016/i.compedu.2014.06.008

[34] O. Talib, M. Nawawi, W. Z. W. Ali, R. Mahmud, and T. P. N. T. Shariman, "Implementing the SEA application for organic chemistry: Arrow-pushing versus electron-moving techniques," in 2014 Information Technology Based Higher Education and Training (ITHET), 2014, pp. 1-5. https://doi.org/10.1109/ITHET.2014.7155719

[35] J. Lee, H. Gu, H. Kim, J. Kim, H. Kim, and H. Kim, "Interactive manipulation of 3D objects using Kinect for visualization tools in education," in 2013 13th International Conference on Control, Automation and Systems (ICCAS 2013), 2013, pp. 1220-1222. https://doi. org/10.1109/ICCAS.2013.6704175

[36] W. W. T. Lam and S. W. I. Siu, "PyMOL mControl: Manipulating molecular visualization with mobile devices," Biochem. Mol. Biol. Educ., vol. 45, no. 1, pp. 76-83, Jan. 2017. https://doi.org/10.1002/bmb.20987

[37] J. Sentongo, R. Kyakulaga, and I. Kibirige, "The Effect of Using Computer Simulations in Teaching Chemical Bonding: Experiences with Ugandan Learners," Int. J. Educ. Sci., vol. 5, no. 4, pp. 433-441, Oct. 2013. https://doi.org/10.1080/09751122.2013.11890105

[38] J. Galván-Ruiz, C. M. Travieso-González, A. Tejera-Fettmilch, A. Pinan-Roescher, L. Esteban-Hernández, and L. Domínguez-Quintana, "Perspective and Evolution of Gesture Recognition for Sign Language: A Review," Sensors, vol. 20, no. 12. 2020. https://doi.org $/ 10.3390 / \mathrm{s} 20123571$

[39] S. Kim, S. Park, and O. Lee, "Development of a Diagnosis and Evaluation System for Hemiplegic Patients Post-Stroke Based on Motion Recognition Tracking and Analysis of Wrist Joint Kinematics,” Sensors, vol. 20, no. 16. 2020. https://doi.org/10.3390/s20164548

[40] C. Paparizos, N. Tsafas, and M. Birbas, "A Zynq-Based Robotic System for Treatment of Contagious Diseases in Hospital Isolated Environment," Technologies, vol. 8, no. 2. 2020. https://doi.org/10.3390/technologies8020028

[41] S. S. Aldosari and D. Marocco, "Using haptic technology for education in chemistry," in 2015 Fifth International Conference on e-Learning (econf), 2015, pp. 58-64. https://doi.or g/10.1109/ECONF.2015.25

[42] S. S. Aldosari and D. Marocco, "Acceptability of technology enhanced learning system in chemistry teachers," in 2017 4th IEEE International Conference on Engineering Technologies and Applied Sciences (ICETAS), 2017, pp. 1-6. https://doi.org/10.1109/ICETAS.201 $\underline{7.8277866}$

[43] P. Lam and A. Tong, "Digital devices in classroom - Hesitations of teachers-to-be," Electron. J. e-Learning, vol. 10, pp. 387-395, 2012.

[44] M. Sauter, D. H. Uttal, D. N. Rapp, M. Downing, and K. Jona, "Getting real: the authenticity of remote labs and simulations for science learning," Distance Educ., vol. 34, no. 1, pp. 37-47, May 2013. https://doi.org/10.1080/01587919.2013.770431 


\section{Authors}

Shaykhah S. Aldosari received her $\mathrm{PhD}$ in Computer Science from the School of Engineering, Computing and Mathematics, University of Plymouth, UK. She works as a lecturer and a researcher in the College of Computer and Information Sciences, Princess Nourah bint Abdulrahman University, Saudi Arabia.

Bogdan Ghita received his PhD in 2005 from University of Plymouth, UK. He is Associate Professor at University of Plymouth and leads the networking area within the Centre for Security, Communications, and Network research. He published over 150 papers, graduated $20 \mathrm{PhD}$ students, and having been principal investigator in a number of industry-led, national, and EU research projects in different computing areas.

Davide Marocco received his $\mathrm{PhD}$ in Artificial Intelligence at the University of Calabria, in Italy. He is currently Associate Professor of Psychometrics at the University of Naples Federico II, and was previously Reader in Cognitive Robotics and Intelligent Systems at the University of Plymouth, in the UK.

Article submitted 2021-08-25. Resubmitted 2021-10-27. Final acceptance 2021-10-28. Final version published as submitted by the authors. 